\title{
RECOLECCIÓN DE MUESTRAS SANGUÍNEAS EN POBLACIONES INDÍGENAS
}

\section{BLOOD SAMPLE COLLECTION IN NATIVE POPULATIONS IN PERU}

\author{
Omar V. Trujillo ${ }^{1, a}$, César Cabezas ${ }^{2, b}$, Luis Marín ${ }^{2, c}$, Jessie Pari C. ${ }^{2, c}$, Oswaldo Salaverry ${ }^{1, d}$
}

Las condiciones de las intervenciones de salud en las regiones con dificultades de accesibilidad geográfica y dificultades socioculturales como las comunidades nativas, requieren un trabajo sostenido y de mayor participación tanto del personal de salud como de la comunidad en general. La existencia de alta rotación de personal en zonas del interior del país ${ }^{(1,2)}$ ha contribuido a que las experiencias relacionadas con su trabajo, no se sistematicen adecuadamente, lo que finalmente deriva en que estas experiencias no contribuyan en la implementación de políticas de salud pública en otras regiones de la selva peruana. El diseño del "Proyecto integral para la atención de la emergencia por hepatitis B en los pueblos kandozi y chapra" que viene desarrollando el Ministerio de Salud (MINSA) a través de la Dirección General de Epidemiología desde el año 2001 responde a las características de la zona. Las actividades se han desarrollado principalmente
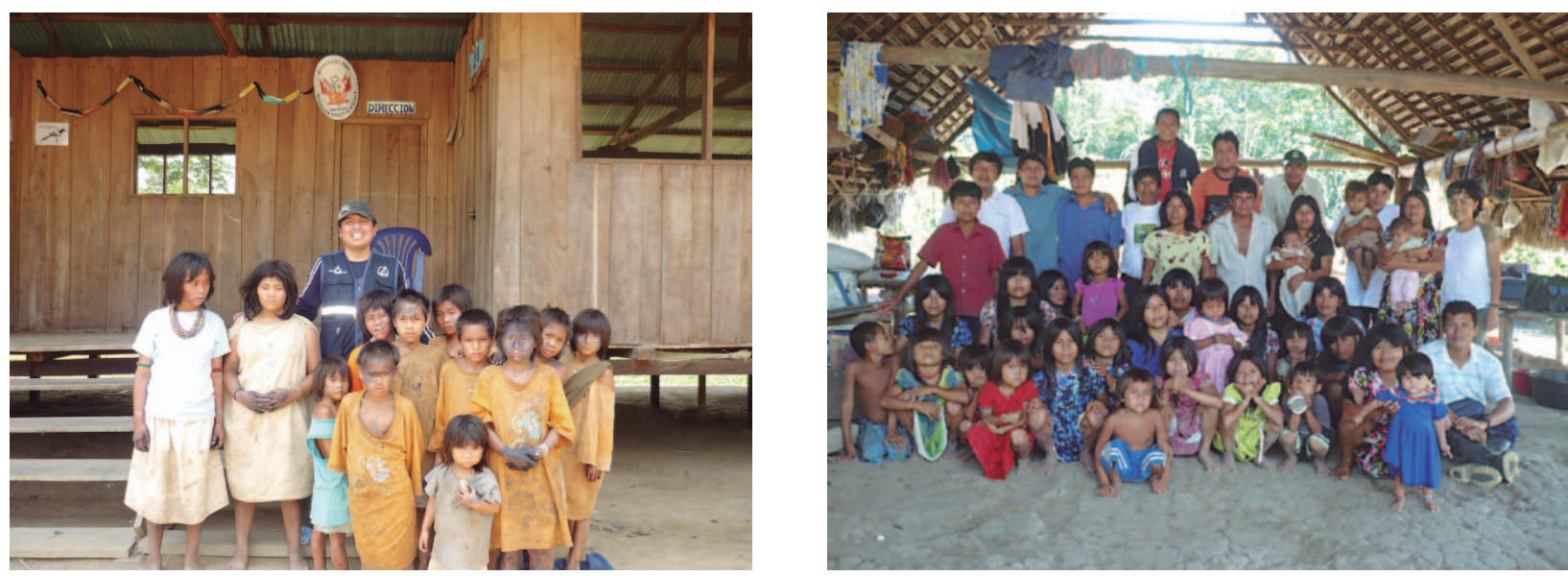

en extramuro, y el personal se ha desplazado continuamente a las comunidades.

En diciembre del año 2009, el MINSA y la sociedad civil firmaron el acta de Lima y el acta de lquitos donde conjuntamente con la Dirección Regional de Salud de Loreto se comprometieron a elaborar el "Plan integral de salud de la provincia Daten del Marañón en el marco del aseguramiento universal con énfasis en la prevención, control y tratamiento de la hepatitis B". Dentro de este plan se consideró como actividad prioritaria realizar un estudio de identificación de la prevalencia de hepatitis $B$ y $D$ y sus factores determinantes de riesgo en los pueblos kandozi y chapra del Datem del Marañón. El trabajo se desarrolló en 69 comunidades kandozi (57/69) y chapra (12/69), de la cuenca del Pastaza y del Morona (Datem del Marañón, Loreto). Actividad realizada mediante la búsqueda activa, en cada comunidad kandozi y chapra,

Figura 1. Población indígena kandozi.

\footnotetext{
Centro Nacional de Salud Intercultural, Instituto Nacional de Salud. Lima, Perú

Centro Nacional de Salud Pública, Instituto Nacional de Salud. Lima, Perú

Médico; ${ }^{\mathrm{b}}$ médico infectólogo; ${ }^{\mathrm{c}}$ tecnólogo médico; ${ }^{\mathrm{d}}$ médico doctor en Medicina

Recibido: 16-11-12 Aprobado: 28-11-12
}

Citar como: Trujillo OV, Cabezas C, Marín L, Pari J, Salaverry O. Recolección de muestras sanguíneas en poblaciones indígenas. Rev Peru Med Exp Salud Publica. 2012;29(4):575-7. 

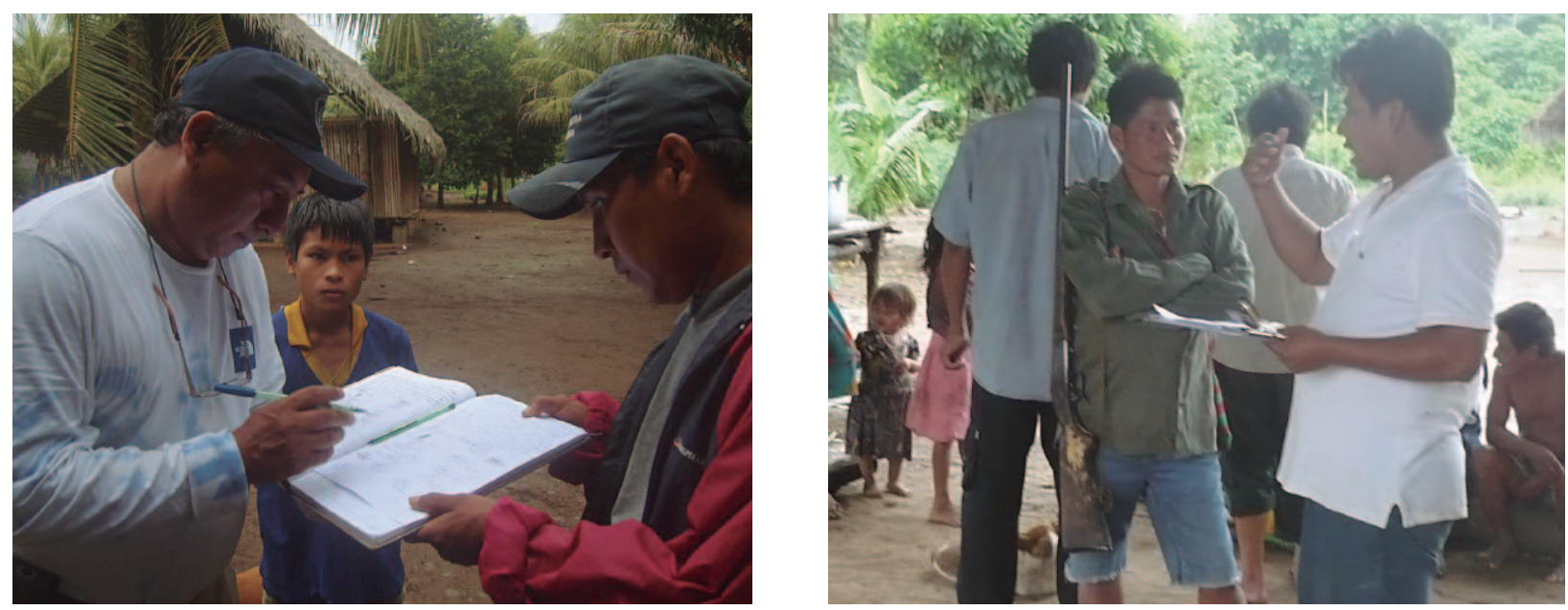

Figura 2. Consentimiento informado y encuesta en población indígena kandozi.

casa por casa, del $100 \%$ de la población. El estudio se puede dividir en tres etapas:

Primera etapa: talleres de sensibilización para el conocimiento de la población sobre la intervención a realizarse, actividad realizada en el mes de marzo, en los ámbitos kandozi y chapra.

Segunda Etapa: obtención del consentimiento informado, recolección de muestras sanguíneas y aplicación de encuesta epidemiológica, realizadas en cuatro cuencas (tres kandozis y una chapra) y a través de cuatro equipos de intervención (brigadas), desarrollando este proceso en abril de 2010.

La obtención, recolección de muestras sanguíneas y encuestas epidemiológicas fue un trabajo realizado con el ingreso de las brigadas a la zona previo consentimiento informado colectivo por parte de los apus y organizaciones indígenas kandozi y chapra, consentimiento informado individual, además de un asentimiento informado para los menores de 18 años, por parte de los padres de familia, al momento del ingreso de las brigadas a las comunidades. Los procesos de consentimiento fueron aprobados por el Comité de Ética del Instituto Nacional de Salud del Perú.

Las muestras sanguíneas fueron transportadas desde las comunidades por vía fluvial hacia el centro de acopio de San Lorenzo, y desde este lugar por vía aérea hacia Yurimaguas, luego se siguió el recorrido por vía terrestre hacia la ciudad de Tarapoto, y desde ahí por vía aérea hacia la ciudad de Lima. Estas muestras fueron analizadas en el Laboratorio de Hepatitis del CNSP del INS. Las muestras se procesaron mediante la técnica ELISA para los marcadores de hepatitis B HBsAg
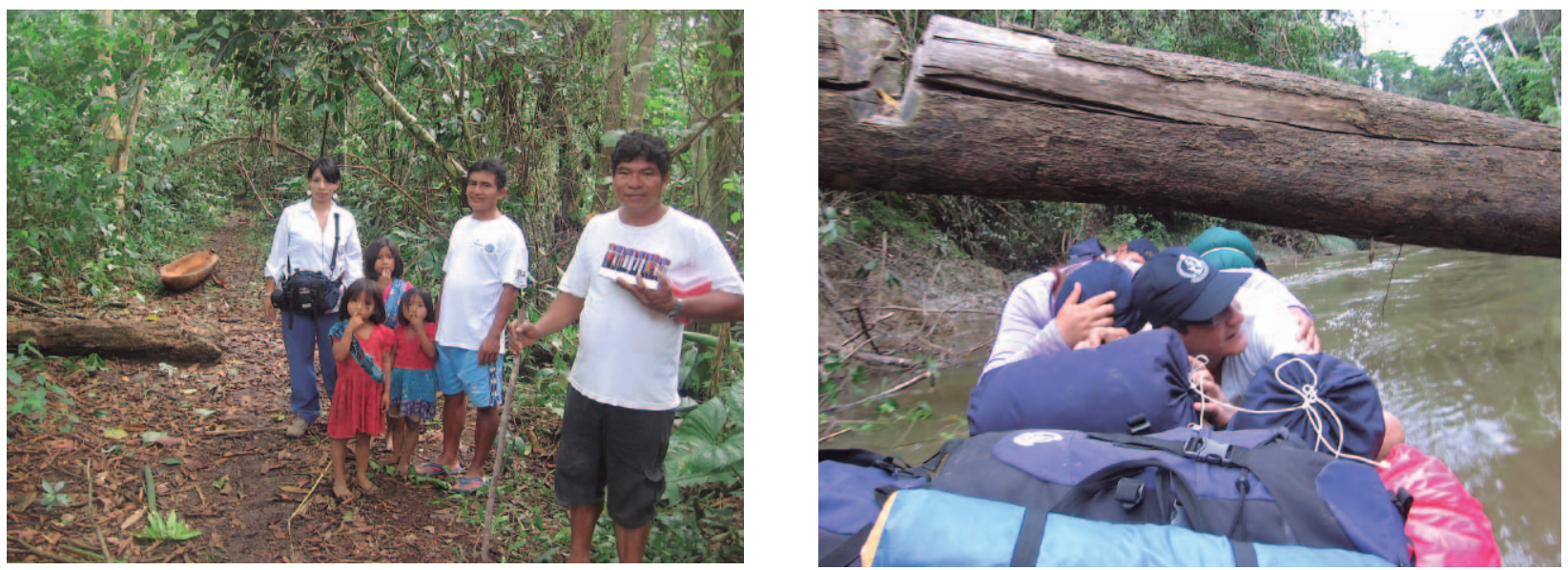

Figura 3. Desplazamiento de la brigada de intervención en población indígena kandozi. 


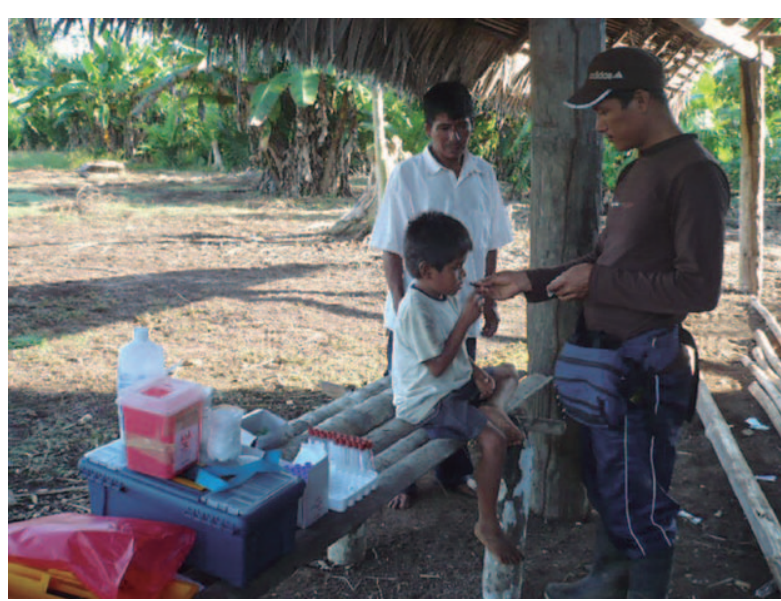

Figura 4. Obtención de muestras en población indígena.

(antígeno de superficie); anti-HBc total (anticuerpos para el antígeno core); anti-HBs, $\mathrm{HBeAg}$, anti-HBe, DNA-HVB, además de las pruebas bioquímicas (TGO, TGP) y carga viral.

Tercera etapa: devolución de resultados a los participantes del estudio y presentación de los resultados a las organizaciones indígenas y autoridades locales de la provincia. Todas las actividades fueron coordinadas por el Instituto Nacional de Salud.

La realización de estudios posteriores sobre cualquier enfermedad que tenga componente social y laboratorial deben involucrar a personal de salud que labora y conoce la zona, ya que este tipo de personal facilita el trabajo con los miembros de la comunidad haciendo más sencillo el desarrollo de cualquier actividad programada ${ }^{(3)}$.

Existe mucha desconfianza y rechazo por parte de los pobladores, en estos ámbitos geográficos, hacia estudios que incluyen actividades de laboratorio (toma de muestras de sangre), ya que según manifiestan los pobladores "nunca les entregan o les entregan muy tarde los resultados", haciendo difícil el desarrollo de las actividades para el personal que labora y se queda en estos ámbitos porque lo asocian con los responsables que desarrollaron estos estudios. En todo estudio al realizar el proceso de devolución de resultados siempre se debe tomar en cuenta al personal de salud que labora en la zona para poder afianzar los lazos de responsabilidad con la comunidad.

Agradecimientos: a los técnicos de laboratorio del Instituto Nacional de Salud, Sres. Miguel Farfán y Edgar Challe por la colaboración en este trabajo, a los padres de familia que autorizaron la participación de sus hijos, y al personal de salud local de la Microrred del Datem del Marañón.

\section{REFERENCIAS BIBLIOGRÁFICAS}

1. Sotomayor R. Globalización y la responsabilidad de los países en desarrollo: el caso de la migración de los profesionales de la salud. Rev Peru Med Exp Salud Publica. 2007;24(3):300-6.

2. Arroyo J. Los sistemas descentrados de recursos humanos en salud: el caso del Perú, 1990-2005. Ciência \& Saúde Coletiva. 2006;11(4):1063-72.

3. Cabezas C. Hepatitis Viral B y Delta en el Perú: epidemiología y bases para su control. Rev Peru Med Exp Salud Publica. 2007;24(4):378-97.

Correspondencia: Omar Trujillo

Dirección: Av. Defensores Morro 2268, Lima 11, Perú.

Teléfono: (511) 7480000 anexo: 1203

Correoelectrónico: otrujillo@ins.gob.pe,otruvil@gmail.com 